\title{
Characteristics of Novel Triplet Spun Yarns Made from Fibers of Differing Fineness
}

\author{
Yo-ICHi MATSUmoto \\ Faculty of Textile Science and Technology, Shinshu University, Ueda 386-8567, Japan \\ Hirokazu Kimura, Takanori Yamamoto \\ Technology Research Institute of Osaka Prefecture, Izumi 594-1157, Japan \\ Toshio Matsuoka \\ Mie Prefectural Science and Technology Promotion Center, Tsu 514-0819, Japan \\ KAZUNARI FUKUSHIMA \\ Daiwabo Neu Co. Ltd., Osaka 541-0056, Japan
}

\begin{abstract}
In order to reduce the hairiness of ring spun yarns and to develop novel multilayered spun yarns, we investigated the properties of triplet spun yarns made from the same size of three rovings with different fiber fineness using an experimental ring spinning frame. The results were: (1) different fiber fineness triplet spun yarn, a new yarn made by combination staple fibers of three different fineness into one twisting process; (2) although triplet spun yarn had a side-by-side structure in the cross section, the central angle made by the assembly of finer fibers was smaller than that of coarser fibers; and (3) in comparison with single yarn, triplet spun yarn had less hairiness and greater strength because of the lower spinning tension of each strand and the twist propagation in each strand.
\end{abstract}

Key words: Characteristics, Composite yarn, Differing fiber fineness, Triplet spun yarn

Introduction

In a comparison of filament yarn, the characteristic of spun yarn is the presence of hairiness. However, 
as the hairiness of the yarn produces faults in the production of fabric, it is desirable to reduce it in spun

yarns. Toward this end, various spinning methods of twin yarn, compact yarn, MVS yarn, and so on have been proposed and reported worldwide [1 - 9]. On the other hand, studies on the arrangements of fibers in blended yarns have been reported by Boswell et.al, Morton, Balasubramanian, and so on [10 - 12].

Fine denier fiber, generally defined by less than 1.1 (dtex) (1.0 (denier)) of fiber fineness, is made by various chemical and mechanical methods. Super fine and fine denier filaments are useful for developing new textile products with the functional properties of reduced weight, high density, softness, wipeability, and so on.

In our previous papers [13], we have reported on the spinning conditions, characteristics, and twist level of novel multilayered spun yarns produced by a modified ring spinning system. In this study, we describe the development and characteristics of novel triplet spun yarns made by combining staple fibers of three different finenesses into one twisting process.

\section{Experiment}

We used three rovings made from viscose rayon fibers of differing fineness as listed in Table 1. The spun yarn size was about 19.7 tex $\left(30 \mathrm{Ne}\right.$ ) and the twist factor was about 43.1 (turns per $\mathrm{cm}$ ) tex ${ }^{1 / 2}(4.5$ (turns per inch) $/ \mathrm{Ne}^{1 / 2}$ ). Figure 1 shows schematic illustrations for various yarn productions using an experimental ring spinning frame. In general, single yarn is made from one staple fiber roving. Twin spun yarn is produced by twisting together two strands that have been separated in the drafting zone, resulting in a yarn with the characteristics of a two-fold structure within a conventional single yarn. As in 
the spinning method for twin spun yarn, triplet spun yarn with a three-ply structure was produced by the use of three staple fiber rovings. In the spinning method shown in Figure 1, the distance from the front roller nip to the yarn formation point at the center position of "b" is shorter than those of the two side positions of "a" and "c", where the distance between the center of the rovings at the three positions of "a", "b", and "c" is set up about $3(\mathrm{~mm})$ using an appropriate guide. In cases in which the three rovings are made from fibers of the same fineness, this yarn is called "same fiber fineness triplet spun yarn" (denoted by "SFTY”). When each supply roving is made from staple fibers of differing fineness, this yarn is called “different fiber fineness triplet spun yarn” (denoted by "DFTY”). Table 2 lists the arrangement of three supply rovings in the spinning of triplet spun yarn. Therefore, DFTY could be made simply by changing the position of each supply roving.

To investigate the geometric position of each fiber strand in the triplet spun yarns, we used a colorless staple fiber (0.2 dtex (0.2 denier)) and two colored staple fibers (0.9 dtex (0.8 denier) in orange and 1.4 dtex (1.3 denier) in black) as listed in Table 1. By manual operation, yarn with a tension of 5 (gf) was wound with a space in between the adjoining coils on a thick cover glass. Under a microscope, we observed longitudinal and cross-sectional views of the yarn, in which each testing was repeated 10 times with different samples. In cross-sectional images, the circle of yarn diameter and the central angle of fiber assembly were measured using scales. Yarn evenness and hairiness were determined using an Uster III automatic evenness tester, with a yarn speed of $25(\mathrm{~m} / \mathrm{min})$, a testing time of $2(\mathrm{~min})$, and with two repetitions. The mechanical properties of the yarns were observed using an Instron constant rate of 
elongation tensile tester with a test length of $250(\mathrm{~mm})$, an extension rate of $300(\mathrm{~mm} / \mathrm{min})$, and 50 tests per

yarn. In the same way, the mechanical properties of fibers with and without the package dyeing were measured by the testing condition with a test length of $20(\mathrm{~mm})$, an extension rate of $20(\mathrm{~mm} / \mathrm{min})$, and 35 tests per fiber.

\section{Results and Discussion}

\section{YARN STRUCTURE}

Figure 2 shows the typical side-by-side structures of various triplet spun yarns. In each image, the circle and three lines in red color indicate the yarn diameter and the boundary lines between three fiber assemblies, respectively. And then, the yarn diameter and the central angle were obtained.

Table 3 lists the characteristics of the yarn structures of various triplet yarns. In samples of SFTY, yarn diameter showed a tendency to decrease with increase of the fiber fineness. It was observed that the width of fiber strand gripped by the front rollers decreased with increase of the fiber fineness because of the smaller number of coarser fibers in the same roving size. In samples of SFTY, the calculated average value of the central angle on fiber fineness of 0.2, 0.9, or 1.4 (dtex) was equal to 120 (degree), respectively. On the other hand, in samples of DFTY, the calculated average central angle were 0.2 (dtex) $=81$ (degree), $0.9($ dtex $)=132.3$ (degree), and $1.4($ dtex $)=146.7$ (degree). The central angle made by the fiber assembly in DFTY increased with increase of the fiber fineness, where the differences between the samples were statistically significant with the level of 0.05 . It is also known that, in blended yarn composed of fibers differing in physical properties, short and coarse fibers tend to lie closer to the surface, while long 
and fine fibers lie at the core. Therefore, if it is necessary to divide the yarn cross-section into equal thirds the same as in the idealized model shown in Figure 1-C, we have to set up and use different roving sizes which vary in the fiber fineness.

In addition, in the arrangement of the three supply rovings, a stable spinning condition for DFTY was obtained by setting up the roving of coarser fibers, 1.4 (dtex), at the center position of "b" as shown in Figure 1. This may be explained by noting that the strand of 1.4 (dtex) had a small number of fibers and, in the spinning triangle formed with the front roller nip and the yarn formation point, the distance from the front roller nip to the yarn formation point at the center position of "b" is shorter than those at the two side positions of "a" and "c". It is also known that twin and triplet spun yarns can have ply and strand twists in spite of the single twisting process, and that the sum of higher ply and lower strand twist levels in yarns are numerically almost equal to the twist level of single yarn of the same count [13]. However, when three rovings made from staple fibers of differing fineness are applied in this spinning method, it may be expected that the twist propagation and the strand twist level will vary with the fiber fineness. Because the coarser fibers with a lower level of strand twist are straight along the sides of the roving arrangement, the edge fibers are easily lost due to their falling away from the yarn formation point. For example, it was observed that the spinning with roving arrangements of $0.9 / 0.2 / 1.4$ or $0.2 / 0.9 / 1.4$ was often interrupted by loss of the fibers in the side roving. So, the unstable spinning condition was brought about with the use of two roving arrangements of 0.9/0.2/1.4 and 0.2/0.9/1.4. In this connection, earlier papers have reported that, in spinning done from triple rovings of fibers of the same type, the central roving occupies a position 
closer to the core, while the ones at the sides show up more prominently at the surface [10], and that fibers in the side roving stay at the surface and contribute more to wild fibers [11]. Namely, the stable spinning condition was also brought about with the use of a roving arrangement of 0.2/1.4/0.9.

\section{YARN EVENESS}

Figure 3 shows the coefficient of variation (CV\%) of thickness on various spun yarns. The CV\% of single yarn increases with increase of the fiber fineness. This may be explained by noting that, regarding the thickness variation of yarn in the same count, as the composition number of coarser fibers is smaller than that of finer fibers, the influence per one coarser fiber is greater than that of one finer fiber. Although the draft ratios are 30 for single yarn and 90 for SFTY (or DFTY), the CV\% of SFTY is smaller than that of single yarn. In general, the CV\% of yarn thickness increases with increase of the draft ratio. The CV\% of DFTY is greater than that of SFTY and is nearly equal to that of single yarn. However, in comparison with the arrangement of supply rovings as listed in Table 2, the CV\% of DFTY 3 (0.2 / 1.4 / 0.9 dtex) is smaller than those of DFTY 1 (0.9 / 0.2 / 1.4 dtex) and DFTY 2 (0.2 / 0.9 / 1.4 dtex).

Therefore, the greater thickness variation of DFTY 1 and 2 may have been caused by the loss of the coarser fibers under the unstable spinning condition. If that is the case, it will be necessary to consider the roving size and the draft ratio for the spinning of triplet spun yarn.

\section{YARN HAIRINESS}


Figure 4 shows the hairiness of various spun yarns. In comparison with single yarns and SFTY made from fibers of the same fineness, SFTY has a tendency toward decrease in the hairiness because of the twist propagation in each fiber strand as mentioned above. The differences are statistically significant. It is also well known that the hairiness of doubled yarn is lower than that of single yarn and that, in comparison with single yarn, twin spun yarn has a lower hairiness. However, we can't check the influences of the fiber fineness because of colorless and colored fibers. In Uster tester, in comparison with yarn made from colorless fibers with the same count, yarn made from colored fibers has a tendency toward decrease in hairiness. Especially, black color has greater influence. In comparison of the roving arrangement, the hairiness of DFTY 3 (0.2 / 1.4 / 0.9 dtex $)$ is smaller than that of DFTY 1 (0.9 / 0.2 / 1.4 dtex $)$ and DFTY 2 (0.2 / 0.9 / 1.4 dtex), but the difference between DFTY3 and DFTY1 is not statistically significant.

\section{TENSILE PROPERTIES}

Table 4 lists the mechanical properties of various fibers. The breaking strength of fibers shows a tendency to decrease with increase of the fiber fineness. And the elongation of fibers increases with increase of the fiber fineness. All the differences are statistically significant.

Figure 5 and 6 show the breaking strength and the elongation of various spun yarns. As shown in Figure 5, the breaking strength of single yarn decreases with increase of the fiber fineness because of the smaller number of coarser fibers in the strand. SFTY have lower irregularity and higher strength than yarns from single roving mainly because of the reduction of irregularity added in drafting by doubling and 
because of the structure being similar to that of doubled yarns as in Siro spinning. In comparison with the arrangement of supply roving, the strength of DFTY 3 (0.2 / 1.4 / 0.9 dtex) is greater than that of DFTY 1 (0.9 / 0.2 / 1.4 dtex) and DFTY 2 (0.2 / 0.9 / 1.4 dtex) with the significant level of 0.05. On the other hand, as shown in Figure 6, the elongation of SFTY is nearly equal to that of single yarn. And the elongation of DFTY is smaller than that of SFTY, but the differences in DFTY are not statistically significant. In comparison with the arrangement of supply rovings, the elongation of DFTY1 is smaller than that of DFTY2 and DFTY3 with the significant level of 0.05. However, it has been reported that, in spinning from triple rovings of fibers of the same type, the average position of the constituent in the yarn section did not have any large effects on the strength or the extension of the yarn [12].

Consequently, in order to improve the evenness, hairiness, and tensile properties of DFTY, it might be useful to consider the cut length of fibers for decreasing hairiness along with decrease of the fiber fineness and the twist level of yarn for propagating a sufficient level of twist into strands composed of coarser fibers.

\section{Conclusions}

To reduce yarn hairiness and develop novel multilayered spun yarns, triplet spun yarns made from fibers of differing fineness (denoted by "DFTY”) using an experimental ring spinning frame were designed and investigated. The results were as follows: (1) DFTY composed of super-fine and/or fine denier fibers could be produced for enhance the functional properties of textile products; (2) with fibers of the same cut length and roving size, as the central angle made by each fiber assembly in the yarn decreased with 
decrease of the fiber fineness, the side view of the fiber assembly displayed irregular width on the yarn surface; (3) the quality of DFTY might be enhanced by decreasing the cut length of fibers with decrease of the fiber fineness and by controlling the roving size and the twist factor to allow an adequate amount of twist propagation in the three staple fiber strands.

Further study is needed to refine the technique of combining three strands made from fibers of differing fineness in the spinning of triplet spun yarn and to develop the practical tests for novel composite yarn.

\section{ACKNOWLEDGMENT}

We wish to thank Mr. K. Shinohara, technician of Shinshu University, Mr. H. Itoh and Mr. K. Minoda, graduate students of Shinshu University, for their assistance.

\section{Literature Cited}

1. Gore, C., The Siro Spun Process, Textile Ind., 146, 64-65 (1982).

2. Happey, F., “Contemporary Textile Engineering”, p.87, Academic Press, London (1982).

3. Su, C., Fang, J., Optimum Drafting Conditions of Non-circular Polyster and Cotton Blend Yarns, Textile Res. J., 76, 441-447 (2006).

4. Salhotra, K., Quality Improvement of Sirospun Yarns Through Use of Finer Rovings, Textile Res. J., 60, 687-689 (1990).

5. Wu, W., Lee, J., Twist in the spinning of a Composite Yarn, Textile Res. J., 65, 522-526 (1995).

6. Wu, W., Lee, J., Effects of Spread Width on the Structure, Properties, and Production of a Composite 
Yarn, Textile Res. J., 65, 225-229 (1995).

7. Fatma, G., Demet, Y., Özer, G., A Comparison of Compact Yarn Properties Produced on Different Systems, Textile Res. J., 76, 226-234 (2006).

8. Guldemet, B., William, O., Comparison of Prperties and Structures of Compact and Conventional Spun Yarns, Textile Res. J., 76, 567-575 (2007).

9. Soe, A., Takahashi, M., Nakajima, M., Matsuo, T., Matsumoto, T., Structure and Properties of MVS Yarns in Comparison with Ring Yarns and Open-End Rotor Spun Yarns, Textile Res. J., 74, 819-826 (2004).

10. Boswell, H. R. and Townend, P. P., Some Observations on the Structure of a Multicolored Yarn, J. Textile Inst., 46, T778-T779 (1955).

11. Morton, W. E., The Structure of Multi-colored Yarns, J. Textile Inst., 47, T239-T240 (1956).

12. Balasubramanian, N., Effect of Processing Factors and Fiber Properties on the Arrangement of Fibers in Blended Yarns, Textile Res. J., 40, 129-141 (1970).

13. Matsumoto, Y., Saito, H., Toriumi, K., Morooka, H., Harakawa, K., Twist Level of Triplet Spun Silk Yarn, J. Seric. Sci., Jpn., 66, 323-329 (1997). 
Table 1 Sample rovings

\begin{tabular}{ccccc}
\hline $\begin{array}{c}\text { Fiber fineness } \\
(\text { dtex })\end{array}$ & $\begin{array}{c}\text { Cut length } \\
(\mathrm{mm})\end{array}$ & $\begin{array}{c}\text { Roving size } \\
\left(\times 10^{2} \text { tex }\right)\end{array}$ & $\begin{array}{c}\text { CV } \\
(\%)\end{array}$ & Color \\
\hline 0.2 & 38 & 5.9 & 3.56 & Colorless \\
0.9 & 38 & 5.9 & 3.30 & Orange \\
1.4 & 38 & 5.9 & 3.35 & Black \\
\hline
\end{tabular}

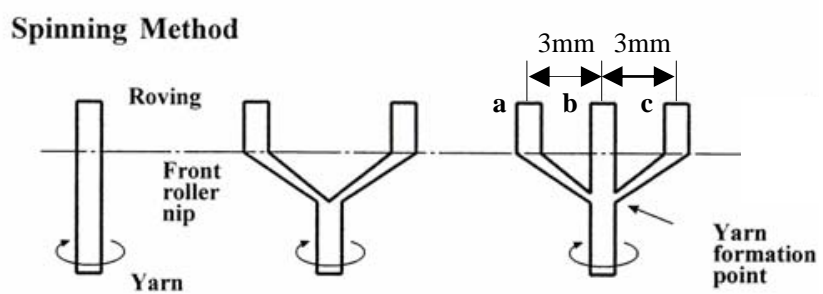

Yarn Cross Section

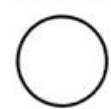

A. Single yarn

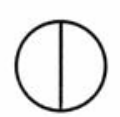

B. Twin spun yarn
C. Triplet spun yarn

Figure 1 Schematic illustrations of various spinning methods.

Table 2 Arrangement of supply rovings

\begin{tabular}{cc}
\hline $\begin{array}{c}\text { Yarn } \\
\text { Sample }\end{array}$ & $\begin{array}{c}\text { Fiber fineness at position a / b / c } \\
\text { (dtex) }\end{array}$ \\
\hline SFTY & $0.2 / 0.2 / 0.2$ \\
1 & $0.9 / 0.9 / 0.9$ \\
2 & $1.4 / 1.4 / 1.4$ \\
3 & \\
DFTY & \\
1 & $0.9 / 0.2 / 1.4$ (or $1.4 / 0.2 / 0.9$ ) \\
2 & $0.2 / 0.9 / 1.4$ (or $1.4 / 0.9 / 0.2$ ) \\
3 & $0.2 / 1.4 / 0.9$ (or $0.9 / 1.4 / 0.2)$ \\
\hline
\end{tabular}




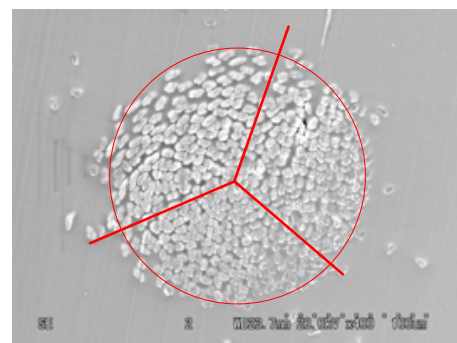

(1) 0.2 / 0.2 / 0.2 dtex

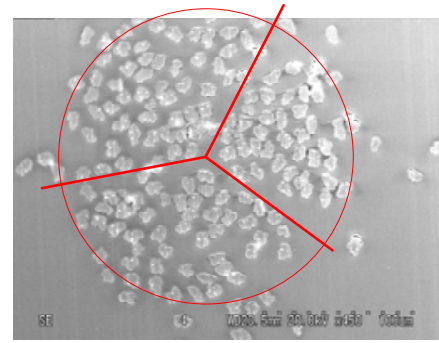

(2) 0.9 / 0.9 / 0.9 dtex

A. Typical structures of SFTY

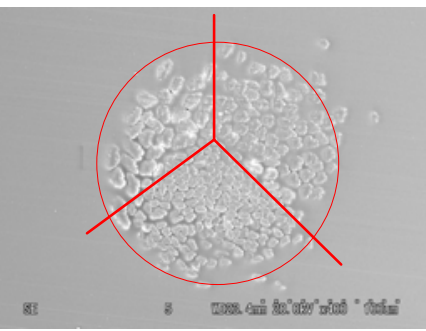

(5) 0.2 / 0.9 / 1.4 dtex

B. Typical structures of DFTY

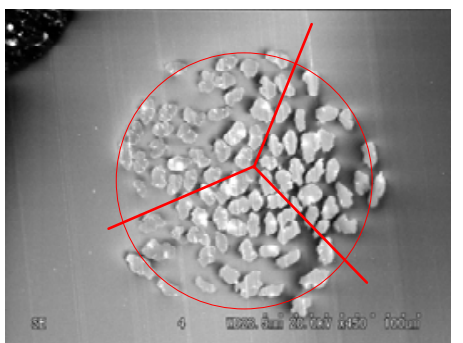

(3) 1.4 / 1.4 / 1.4 dtex

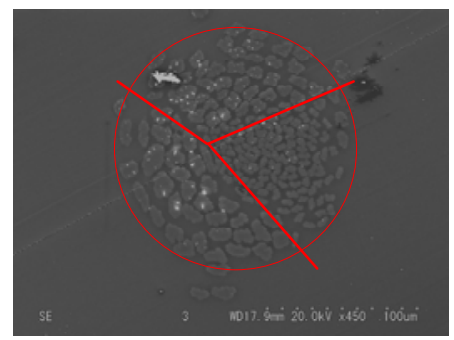

(4) 0.9 / 0.2 / 1.4 dtex

Figure 2 Typical images of various triplet spun yarns

Table 3 Characteristics of yarn cross section

\begin{tabular}{|c|c|c|c|c|}
\hline \multirow{2}{*}{$\begin{array}{c}\text { Yarn sample } \\
\text { (Roving arrangement) }\end{array}$} & \multicolumn{2}{|c|}{ Diameter } & \multicolumn{2}{|c|}{ Central angle of fiber fineness } \\
\hline & Mean $(\mu \mathrm{m})$ & CV (\%) & Mean (degree) & CV (\%) \\
\hline SFTY & & & & \\
\hline $1(0.2 / 0.2 / 0.2)$ & 189 & 8.9 & $113 / 132$ / 115 & $31.1 / 21.6 / 29.0$ \\
\hline $2(0.9 / 0.9 / 0.9)$ & 176 & 11.3 & $122 / 124$ / 114 & $14.7 / 13.7 / 13.7$ \\
\hline $3(1.4 / 1.4$ / 1.4) & 178 & 12.4 & $118 / 126 / 116$ & $15.5 / 15.1 / 15.8$ \\
\hline DFTY & & & $\lceil *\rceil[*]$ & \\
\hline $1(0.9 / 0.2 / 1.4)$ & $* \leftarrow 188$ & 12.0 & $128 / 84 / 148$ & 23.7 / 33.9 / 19.2 \\
\hline $2(0.2 / 0.9 / 1.4)$ & * 174 & 12.1 & 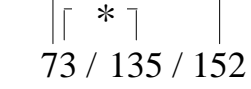 & 34.4 / 20.0 / 14.7 \\
\hline $3(0.2 / 1.4 / 0.9)$ & $L 169$ & 6.7 & $86 / 140 / 134$ & 35.9 / 18.3 / 16.2 \\
\hline
\end{tabular}

$*: \mathrm{p}=0.05$ level 


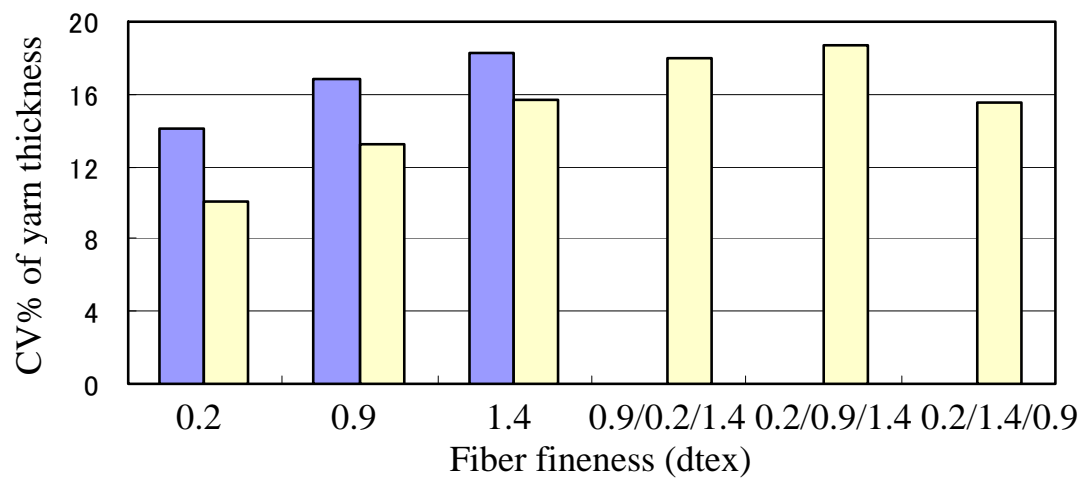

Figure $3 \mathrm{CV} \%$ of various yarns

( $\square$ : single yarn, $\square$ : triplet spun yarn).

Table 4 Characteristics of various fibers

\begin{tabular}{|c|c|c|}
\hline Fiber fineness (dtex) & Mean & $\mathrm{CV} \%$ \\
\hline \multicolumn{3}{|l|}{0.2 (without dyeing) } \\
\hline Strength (gf/dtex) & $=2.60$ & 15.5 \\
\hline Elongation (\%) & 15.5 & 8.3 \\
\hline 0.9 (with dyeing) & & \\
\hline Strength (gf/dtex) & $*=2.11 *$ & 18.9 \\
\hline Elongation (\%) & $17.4 \Rightarrow *$ & 13.7 \\
\hline 1.4 (with dyeing) & & \\
\hline Strength (gf/dtex) & $L 2.35^{*}$ & 11.7 \\
\hline Elongation (\%) & $19.0 \sqsupseteq$ & 6.8 \\
\hline
\end{tabular}

$*: \mathrm{p}=0.05$ level 


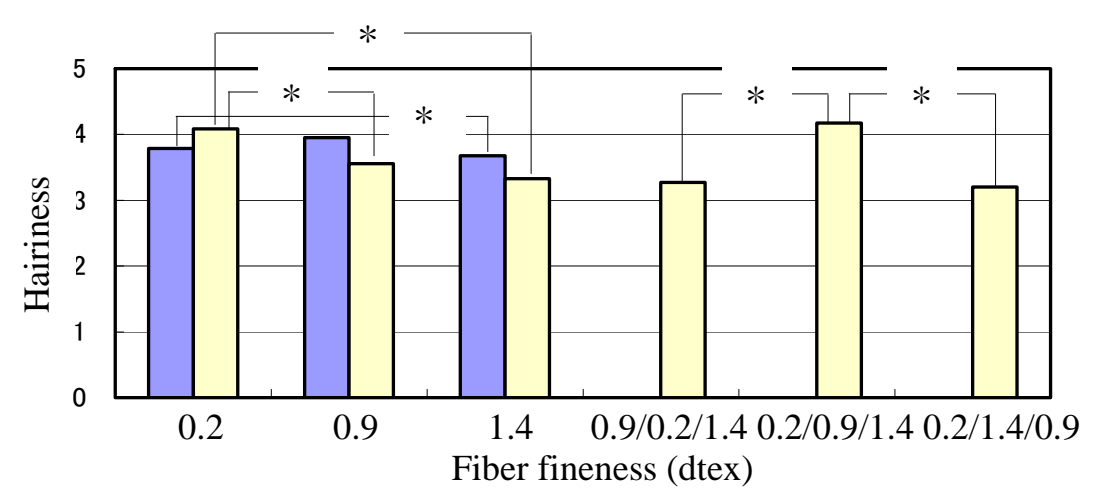

Figure 4 Hairiness of various yarns

( $\square$ : single yarn, $\square$ : triplet spun yarn, $*: \mathrm{p}=0.05$ level ).

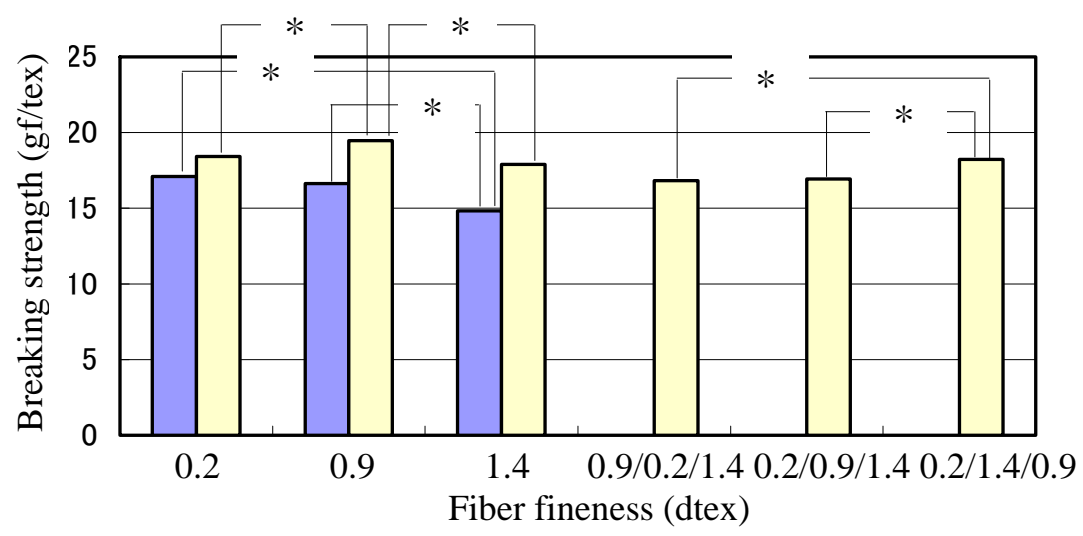

Figure 5 Breaking strength of various yarns

( $\square$ : single yarn, $\square$ : triplet spun yarn, $*: \mathrm{p}=0.05$ level).

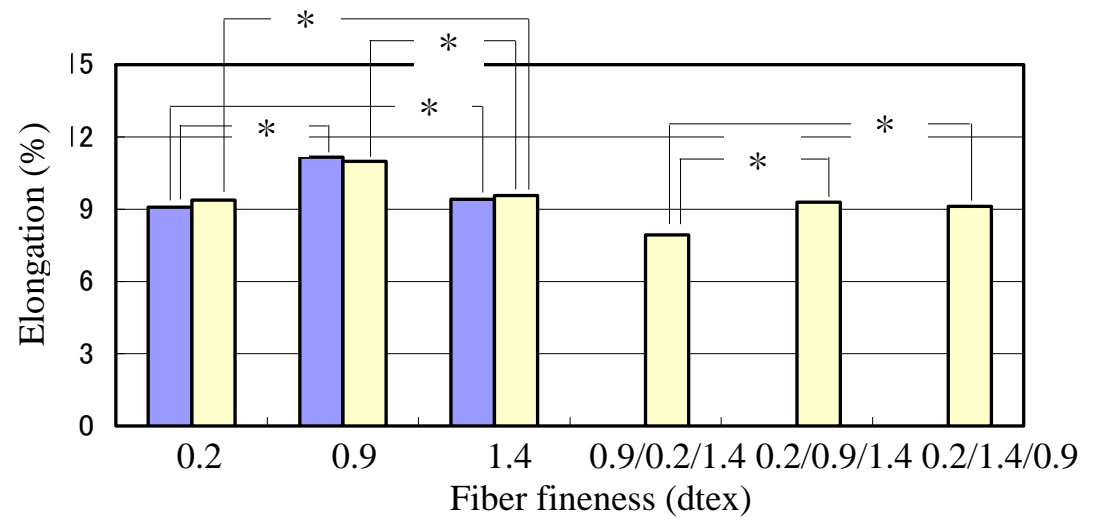

Figure 6 Elongation of various yarns

( $\square$ : single yarn, $\square$ : triplet spun yarn, $*: \mathrm{p}=0.05$ level). 